\title{
Primary malignant lymphoma of the talus: A case report and review of the literature
}

\author{
SHUNSUKE SATO $^{1 *}$, YOICHI KANEUCHI $^{1 *}$, MICHIYUKI HAKOZAKI $^{1}$, \\ HITOSHI YAMADA ${ }^{1}$, SATOSHI KAWANA ${ }^{2}$, OSAMU HASEGAWA ${ }^{3}$ and SHINICHI KONNO ${ }^{1}$ \\ Departments of ${ }^{1}$ Orthopaedic Surgery, ${ }^{2}$ Pathology and Diagnostic Pathology, and ${ }^{3}$ Radiology, \\ Fukushima Medical University School of Medicine, Fukushima 960-1295, Japan
}

Received August 17, 2016; Accepted August 3, 2017

DOI: $10.3892 /$ mco.2017.1362

\begin{abstract}
Malignant lymphoma commonly occurs in adults, with a peak incidence between the seventh and ninth decades of life. Although malignant lymphoma usually occurs in the lymph nodes, it rarely occurs primarily in the bone. We herein describe an extremely rare case of primary malignant lymphoma of the talus in a 74-year-old man. Although plain radiographs showed no abnormality, gadolinium-enhanced magnetic resonance imaging (MRI) revealed a well-circumscribed intra- and extraosseous tumor of the talus. ${ }^{18} \mathrm{~F}$-fluorodeoxyglucose (FDG) positron emission tomography/ MRI revealed a marked increase of FDG uptake in the right ankle and the right inguinal lymph nodes. As the tumor was diagnosed as diffuse large B-cell lymphoma by core needle biopsy, combination therapy with chemo- and radiotherapy was initiated. The patient achieved complete remission, with no sign of recurrence at 8 months after initial chemoradiotherapy. Since primary malignant lymphoma of the bone is chemo- and radiosensitive and has a good prognosis, accurate staging by radiological investigation as well as correct pathological diagnosis by biopsy are required for optimal treatment.
\end{abstract}

\section{Introduction}

Malignant lymphoma (ML) is a hematological malignancy originating from lymphocytes. In Japan, the incidence of ML is estimated to be 22,000 individuals per year (1). ML commonly occurs in adults, with a peak incidence between the seventh and ninth decades of life (2). Although ML usually occurs primarily

Correspondence to: Dr Michiyuki Hakozaki, Department of Orthopaedic Surgery, Fukushima Medical University School of Medicine, 1 Hikarigaoka, Fukushima-shi, Fukushima 960-1295, Japan

E-mail:paco@fmu.ac.jp

"Contributed equally

Key words: primary malignant lymphoma of bone, talus, diffuse large B-cell lymphoma, ${ }^{18} \mathrm{~F}$-fluorodeoxyglucose, positron emission tomography/magnetic resonance imaging in the lymph nodes, it rarely occurs primarily in the bone (primary malignant lymphoma of bone; PLB). PLB accounts for $\sim 5 \%$ of extranodal lymphomas and 3-7\% of primary malignant bone tumors $(3,4)$. PLB usually occurs between the ages of 40 and 60 years and displays a slight male predominance (male: female ratio, 1.5:1) $(3,5,6)$. Patients with PLB frequently lack systemic symptoms (i.e., fever, night sweats and weight loss; B symptoms); conversely, they commonly complain of local symptoms, such as pain, swelling and pathological fractures (7). Therefore, clinically diagnosing PLB without B symptoms is difficult. The most frequent site of PLB is the femur, followed by the pelvis, tibia, humerus and spine $(7,8)$; small bones of the hand and foot, particularly the talus, are rare sites $(4,5)$. We herein report an exceedingly rare case of primary diffuse large B-cell lymphoma (DLBCL) occurring in the talus and discuss it with reference to the literature.

\section{Case report}

A 74-year-old Japanese man, with a previous medical history of diabetes, hypertension and prostatic hypertrophy, presented to the primary hospital with a 5-month history of pain, fever, swelling of the right ankle and a right inguinal lump. Plain radiography of the right ankle revealed no abnormality (Fig. 1A). Magnetic resonance imaging (MRI) revealed a well-circumscribed intraosseous tumor $(8.0 \times 6.9 \times 4.3 \mathrm{~cm})$ extending to the surrounding soft tissue in front of the talus, exhibiting low intensity on both T1-and T2-weighted imaging (WI), and uniform enhancement on gadolinium-enhanced T1-weighted fat-suppression imaging (Fig. 1B-D). A primary soft tissue tumor was initially suspected and the patient was referred to the Fukushima Medical University Hospital (Fukushima, Japan). The laboratory findings at initial presentation indicated mild anemia (hemoglobin: $12.9 \mathrm{~g} / \mathrm{dl}$; normal range, $13.5-17.5 \mathrm{~g} / \mathrm{dl}$ ) and elevated lactate dehydrogenase (LDH) level (310 IU/1; normal range, 120-242 IU/l). The liver and renal function tests showed no abnormalities. Computed tomography (CT) of the chest, abdomen and pelvis showed bilateral renal cysts and right inguinal lymphadenopathy. Whole-body fluorine-18-fluorodeoxyglucose $\left({ }^{18} \mathrm{~F}-\mathrm{FDG}\right)$, positron emission tomography (PET)/MRI revealed increased FDG uptake in the right talus and its surrounding soft tissue [maximum standardized uptake value $\left(\mathrm{SUV}_{\max }\right)$ : 28.7], the 

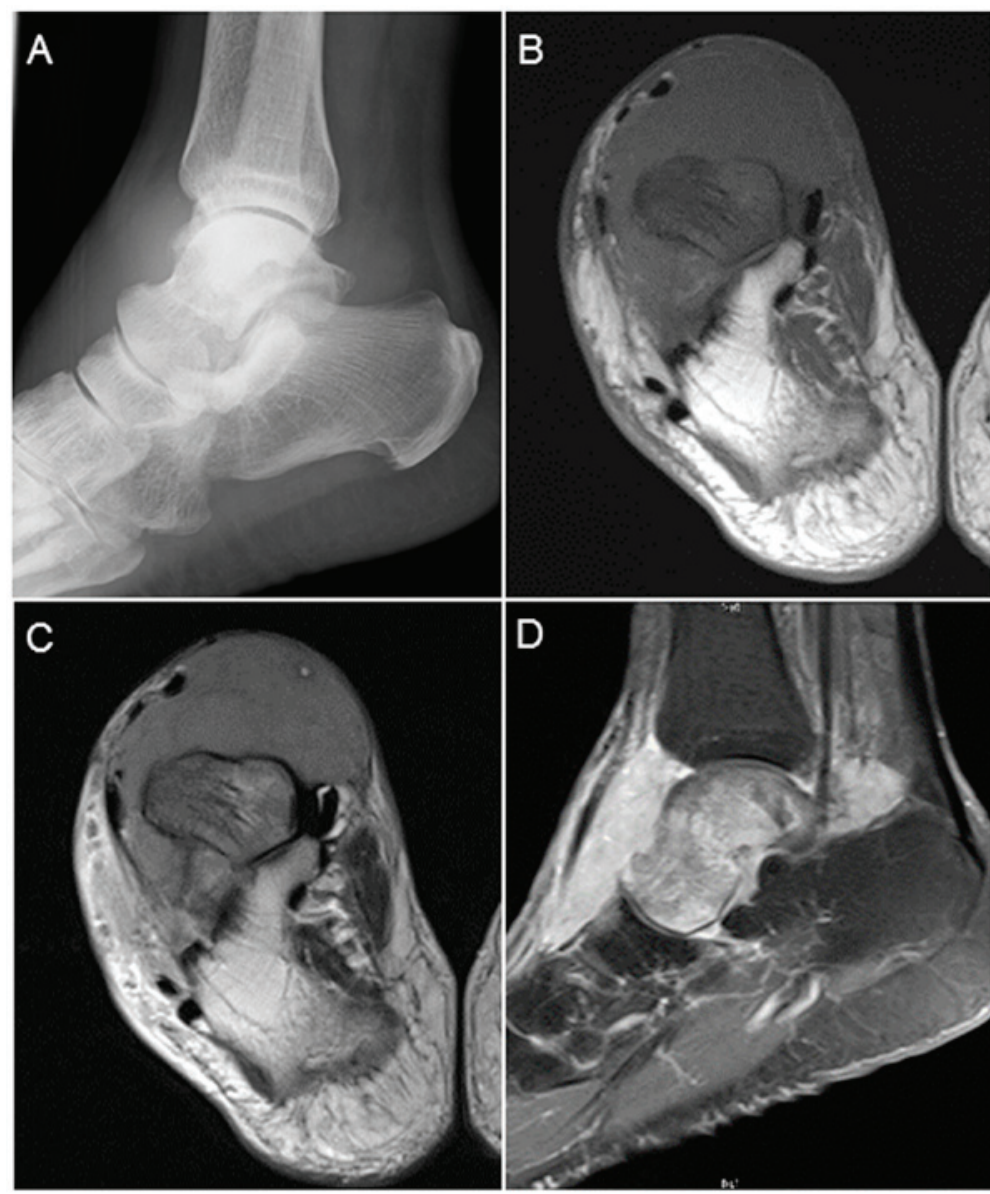

Figure 1. (A) Plain radiograph of the right ankle (lateral view) revealed no bone abnormality. Magnetic resonance imaging of the right ankle revealed a bone tumor of the talus with extraosseous invasion, exhibiting low intensity on (B) T1-weighted images (axial view) and (C) T2-weighted images (axial view) and (D) uniform enhancement on gadolinium-enhanced T1-weighed fat-suppression images (sagittal view).

right inguinal lymph node (5.9), and the right popliteal lymph nodes (3.5 and 2.2) (Fig. 2A-C). Since a malignant bone tumor was initially suspected, core needle biopsy of the right talus was performed. The histopathological examination of the tumor revealed diffuse growth of large anaplastic cells with round or oval nuclei. Immunohistochemically, the tumor cells were positive for CD45, CD20, B-cell lymphoma (bcl)-6, vimentin, Forkhead box protein-P1 and multiple myeloma oncogene-1, but negative for CD3, CD5, CD10, CD34, bcl-2, and Ebstein-Barr virus-encoded RNA (Fig. 3A-H). The MIB-1 labeling index was $\sim 70 \%$ (Fig. 3I). Additionally, the level of serum soluble interleukin-2 receptor (sIL-2R) was markedly elevated $(1,890 \mathrm{U} / \mathrm{ml}$; normal range, $122-496 \mathrm{U} / \mathrm{ml})$. Histopathological and imaging examinations led to the diagnosis of primary DLBCL of the talus with metastasis to the right inguinal and popliteal lymph nodes, or stage IIE according to the Ann Arbor classification. The patient received eight courses of R-CHOP chemotherapy (rituximab $250 \mathrm{mg} / \mathrm{m}^{2} /$ course, cyclophosphamide $430 \mathrm{mg} / \mathrm{m}^{2} /$ course, doxorubicin $25 \mathrm{mg} / \mathrm{m}^{2} /$ course, vincristine $0.7 \mathrm{mg} / \mathrm{m}^{2} /$ course and oral prednisolone $60 \mathrm{mg}$ on days $1-5$, every 3 weeks) without complications at the local hospital. Although chemotherapy was effective and the tumor was reduced in size, a pathological fracture of the talus occurred during the chemotherapy; thus, the patient was forced to walk in a non-weight-bearing manner using crutches for 6 weeks. Six months after the first treatment, additional radiotherapy (a total of $40 \mathrm{~Gy}$ in 20 fractions) was performed on the right ankle. Eight months after the radiotherapy, whole-body ${ }^{18} \mathrm{~F}$-FDG PET/CT detected no FDG uptake in the right inguinal and popliteal lymph nodes or the right talus, indicating a complete response (CR), and the patient showed no symptoms or signs of local recurrence or metastasis (Fig. 4A and B).

\section{Discussion}

PLB is defined as a neoplasm composed of malignant lymphoid cells, producing one or more masses within the bone, without any supraregional lymph node involvement or other extranodal lesions, excluding regional lymph node involvement (9). In the present case, the talus tumor was diagnosed as primary, as the size of the tumor mass was the largest and the FDG uptake of the talus was the highest; it exhibited the mean uptake of PLB as described by Wang et al (10), with an $\mathrm{SUV}_{\max }$ of $15 \pm 11.82$. The inguinal and popliteal lymph nodes were considered to be compatible with regional lymph node metastasis from the talus tumor. To the best of our knowledge, only 5 cases of PLB of the talus have been previously reported in the English literature, namely 1 case of multifocal and 4 cases of unifocal lesions, as in the present case (Table I) $(3,8,11-13)$.

The radiological characteristics of PLB are variable and non-specific $(12,14,15)$. Imaging usually shows an 
Table I. Summary of previously reported cases of PLB of the talus.

\begin{tabular}{|c|c|c|c|c|c|}
\hline Study (Refs.) & $\begin{array}{l}\text { Age (years)/ } \\
\text { gender }\end{array}$ & Treatment & $\begin{array}{l}\text { Histological } \\
\text { type }\end{array}$ & Prognosis & $\begin{array}{c}\text { Follow-up } \\
\text { duration (months) }\end{array}$ \\
\hline Present case & $74 / \mathrm{M}$ & $\mathrm{CT}+\mathrm{RT}$ & DLBCL & $\mathrm{CR}$ & 8 \\
\hline Bansal et al (11) & $32 / \mathrm{M}$ & $\mathrm{CT}+\mathrm{RT}$ & DLBCL & $\mathrm{CR}$ & 3 \\
\hline Patel et al (12) & $6 / \mathrm{M}$ & $\mathrm{CT}$ & DLBCL & $\mathrm{CR}$ & 18 \\
\hline Nickisch et al (8) & $58 / \mathrm{M}$ & $\mathrm{CT}+\mathrm{RT}$ & DLBCL & $\mathrm{CR}$ & 18 \\
\hline Kobayashi et al (13) & 68/M & $\mathrm{RT}+\mathrm{CT}$ & DLBCL & NA & 6 \\
\hline
\end{tabular}

PLB, primary lymphoma of the bone; CT, chemotherapy; RT, radiotherapy; DLBCL, diffuse large B-cell lymphoma; CR, complete remission; NA, not available.

A

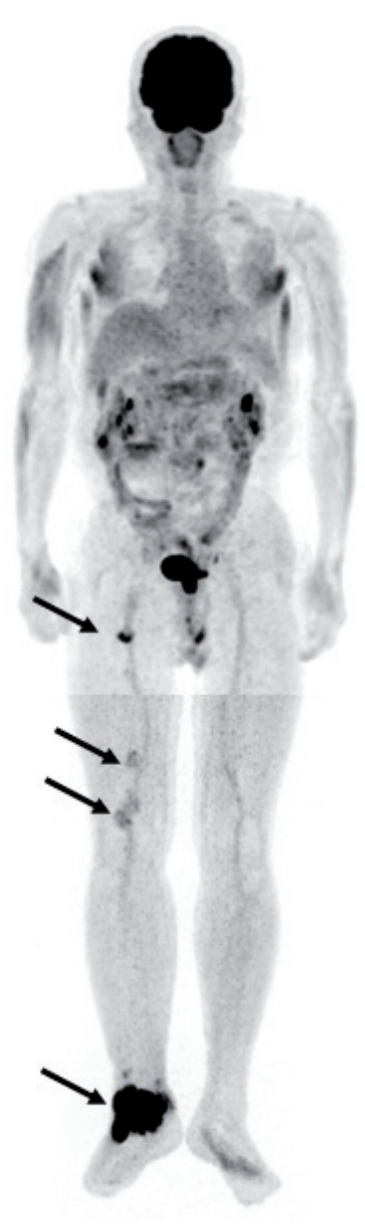

$B$
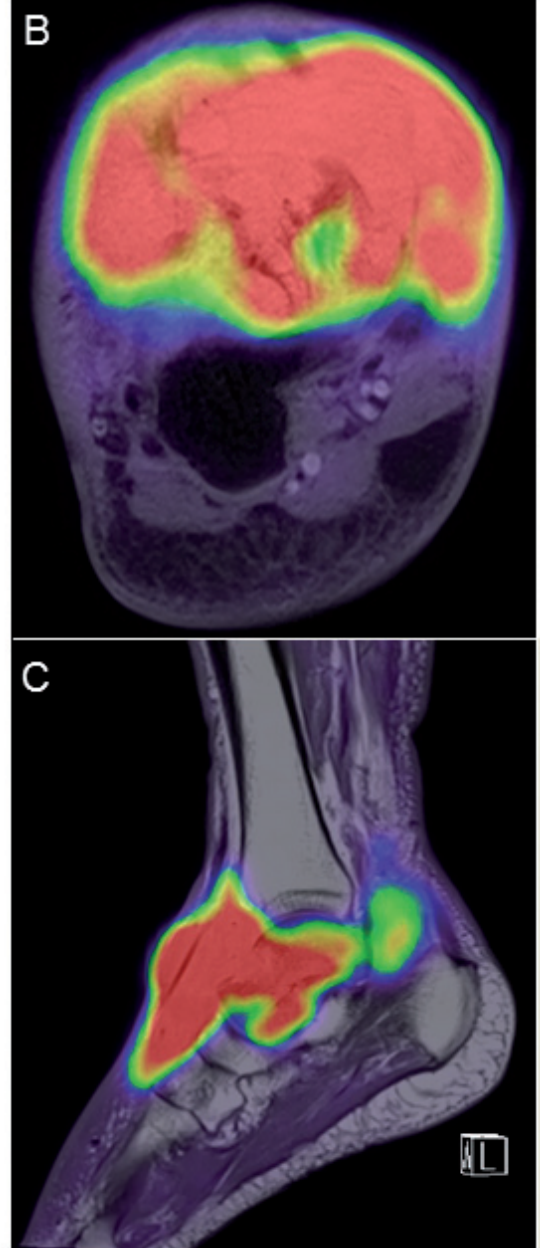

Figure 2. (A) Whole-body ${ }^{18} \mathrm{~F}$-fluorodeoxyglucose (FDG) positron emission tomography (PET) imaging showed abnormal FDG uptake in the right talus (maximum standardized uptake value, 28.7), right inguinal lymph node (5.9) and right popliteal lymph nodes (3.5 and 2.2) (arrows). (B and C) ${ }^{18} \mathrm{~F}-\mathrm{FDG}$ PET/magnetic resonance imaging revealed FDG uptake of the right talus by both the intraosseous lesion and the surrounding soft tissue (B, axial view; $\mathrm{C}$, sagittal view).

osteolytic lesion permeated with a moth-eaten pattern of destruction $(4,16)$. Mixed lytic and sclerotic lesions are less common, and sclerotic-only lesions are rare (16); if the cortex is uninvolved, plain radiographs may show no abnormality $(9,16)$. MRI is very useful for evaluating the extent of surrounding soft tissue and bone marrow involvement $(12,16)$. MRI in PLB usually shows an abnormality of the bone marrow exhibiting low intensity on T1- and high intensity on T2-WI. Although reactive changes, including peritumoral edema of the bone marrow, exhibit high intensity on T2-WI, the lesion including fibrosis typically shows low intensity. Contrast-enhanced MRI shows enhancement within the lesion $(4,16)$. The differential diagnosis for these radiological findings have been reported to include Ewing's sarcoma, multiple myeloma, osteomyelitis, osteonecrosis and Paget's disease of the bone $(5,8,12,16)$. As MRI findings are also variable and non-specific, imaging 


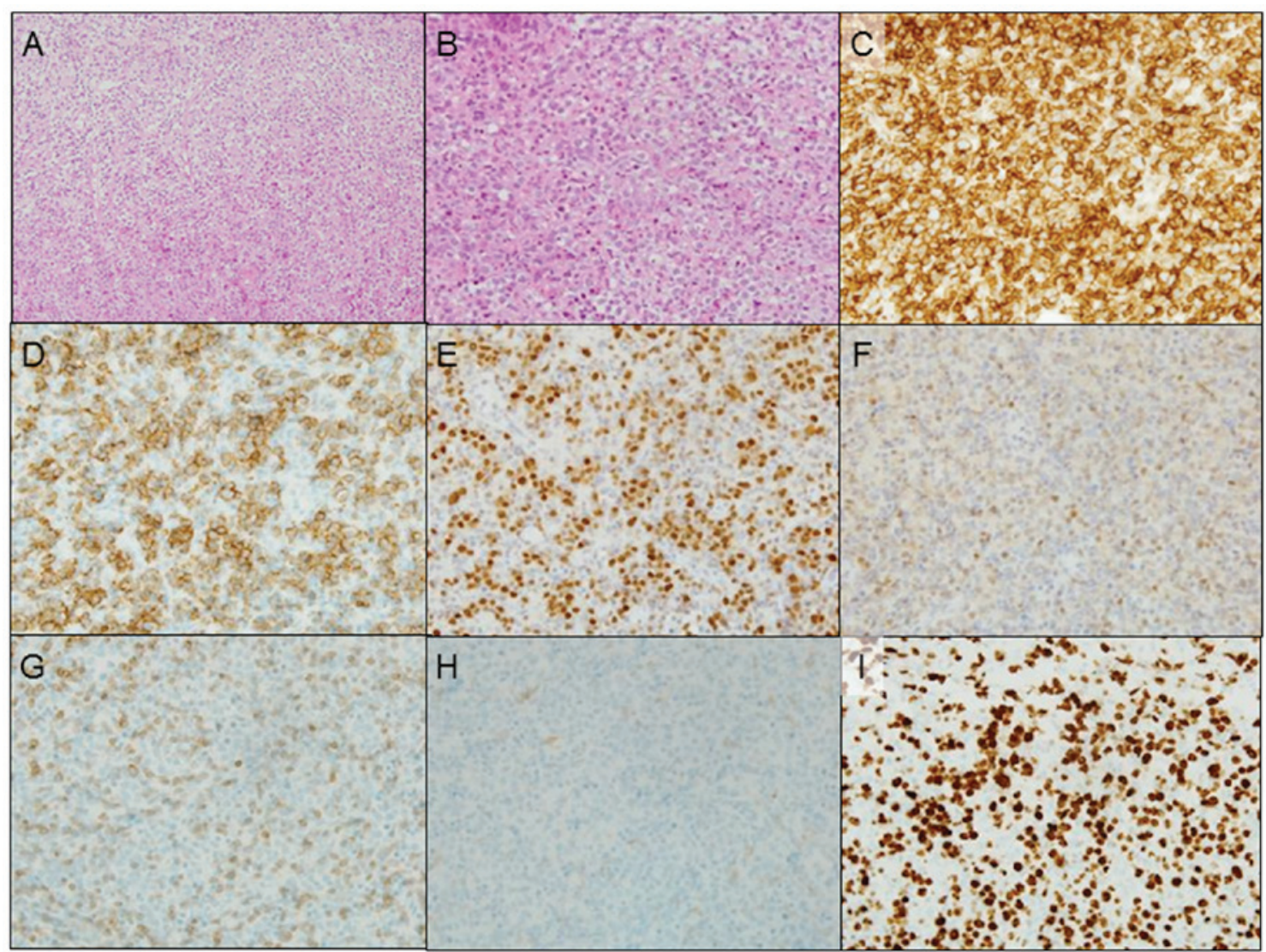

Figure 3. (A) Low- and (B) high-power microscopic fields revealed diffuse proliferation of atypical cells with clear nucleoli in large oval, irregular and cleaved nuclei arranged in a fibrous stroma (hematoxylin and eosin staining; magnification: A, x10 and B, x200). Immunohistochemically, the tumor cells were positive for (C) CD45, (D) CD20, (E) multiple myeloma oncogene-1 and (F) B-cell lymphoma 6, but negative for (G) CD3 and (H) CD10. (I) The MIB-1 labeling index was 70\% .

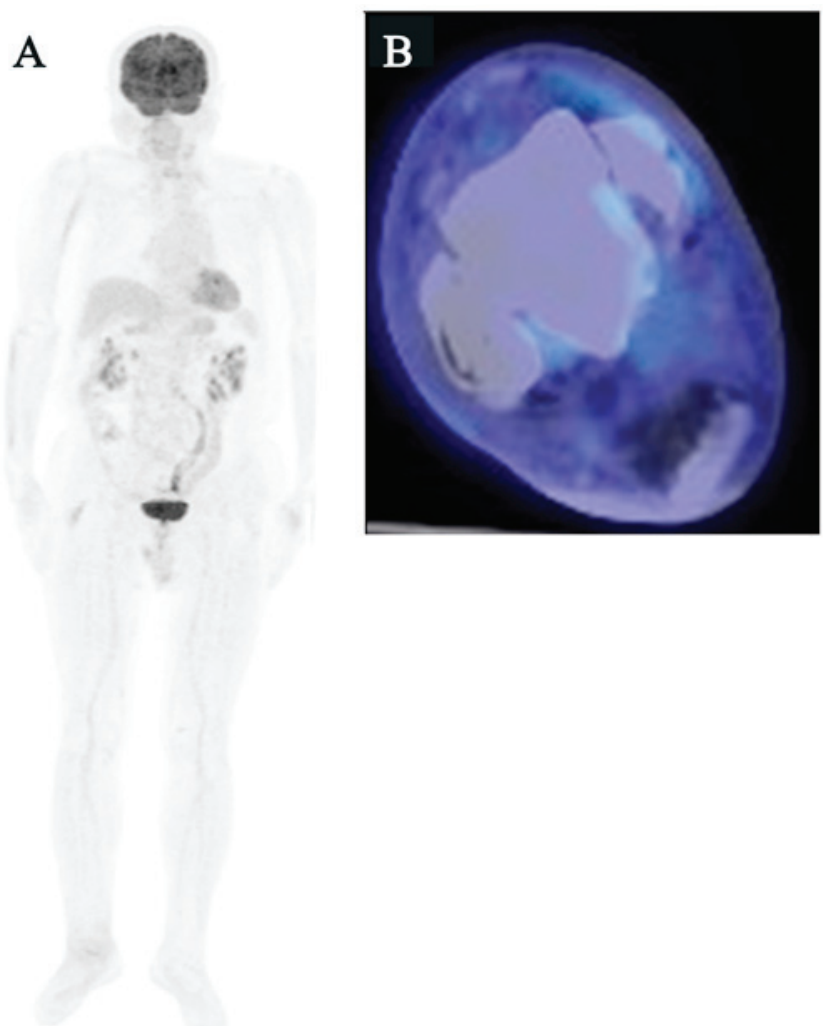

Figure 4. Eight months after the initial chemoradiotherapy, (A) whole-body ${ }^{18} \mathrm{~F}$-fluorodeoxyglucose (FDG) positron emission tomography (PET) imaging and (B) ${ }^{18}$ F-FDG PET/computed tomography (axial view) detected no abnormal FDG uptake in the whole body, including the right talus. 
examinations alone may lead to misdiagnosis $(4,16,17)$. For osteolytic lesions, however, serum sIL-2R has been reported to be a useful marker that distinguishes PLB from other bone lesions (18). As serum sIL-2R has shown higher sensitivity (0.95) and specificity (0.70) compared with other laboratory data, such as LDH and C-reactive protein (18), this marker should be measured when PLB is suspected.

PET scans play an important role in the diagnosis, staging and evaluation of the response to treatment of PLB $(10,19)$. The diagnostic sensitivity of PET/CT has been reported to be significantly higher compared with that of CT (98.9 vs. $43.2 \%$, respectively) (8). As PET/MRI has been reported to show higher sensitivity for detecting bone marrow involvement of ML compared with PET/CT and bone scintigraphy $(19,20)$, $\mathrm{PET} / \mathrm{MRI}$ is useful for detecting osseous involvement in ML, including PLB. Although 3 of the 5 previously reported cases did not undergo FDG PET scans (11-13), PET/MRI or PET/CT is quite useful for accurate staging of PLB, as well as evaluation of the therapeutic effects.

Among PLBs, DLBCL is the most common subtype and accounts for $68-80 \%$ of the cases $(7,21-23)$. The current standard chemotherapy for patients with DLBCL consists of cyclophosphamide, doxorubicin, vincristine and prednisone (CHOP) or CHOP with rituximab (R-CHOP) (24). As regards the treatment outcome of PLB, combination chemotherapy with local radiotherapy has been reported to be superior to radiotherapy alone $(7,25,26)$. Conversely, surgical resection, as a local treatment, has a limited indication only for spinal cases with progressive neurological disorder or cases with pathological fractures in the extremities (27). In the present case, combined chemotherapy with R-CHOP followed by irradiation was performed and the tumor exhibited a CR; therefore, these treatments were considered to be beneficial.

In conclusion, PLB is exceedingly rare and its radiological findings are variable and non-specific; therefore, accurate diagnosis without pathology is quite difficult in the majority of the cases. Since PLB in the early stages is relatively curable by appropriate multimodal treatment using chemo- and radiotherapy, correct diagnosis and staging by histological and imaging examinations are crucial. When radiologically diagnosing bone tumors, including those of the talus, clinicians should consider the possibility of PLB.

\section{References}

1. Matsuda A, Matsuda T, Shibata A, Katanoda K, Sobue T and Nishimoto H; Japan Cancer Surveillance Research Group: Cancer incidence and incidence rates in Japan in 2008: A study of 25 population-based cancer registries for the Monitoring of Cancer Incidence in Japan (MCIJ) project. Jpn J Clin Oncol 44 388-396, 2014.

2. Katanoda K, Hori M, Matsuda T, Shibata A, Nishino Y, Hattori M, Soda M, Ioka A, Sobue T and Nishimoto H: An updated report on the trends in cancer incidence and mortality in Japan, 1958-2013. Jpn J Clin Oncol 45: 390-401, 2015.

3. Mikhaeel NG: Primary bone lymphoma. Clin Oncol (R Coll Radiol) 24: 366-370, 2012.

4. Mulligan ME, McRae GA and Murphey MD: Imaging features of primary lymphoma of bone. AJR Am J Roentgenol 173: 1691-1697, 1999

5. Ibáñez M, Cortina B, Gómez V, Alvaro-Gracia JM, Reina T and Castañeda S: Aggressive transformation of a quiescent primary bone lymphoma simulating Paget's disease. Clin Exp Rheumatol 26: 133-135, 2008.
6. Bayrakci K, Yildiz Y, Saglik Y, Altay M, Ogüt H, Samur M and Erekul S: Primary lymphoma of bones. Int Orthop 25: 123-126, 2001.

7. Beal K, Allen L and Yahalom J: Primary bone lymphoma: Treatment results and prognostic factors with long-term follow-up of 82 patients. Cancer 106: 2652-2656, 2006.

8. Nickisch F, Tashjian RZ, Ritter M, Terek RM and DiGiovanni CW: Primary malignant non-Hodgkin lymphoma of the talus: A case report. Foot Ankle Int 26: 568-571, 2005.

9. Unni KK and Hogendoorn PCW: Malignant lymphoma. In: Fletcher CDM, Unni KK, Mertens F, (eds): Pathology and Genetics: Tumours of Soft Tissue and Bone. Lyon, France: IARC Press; pp306-pp308, 2002.

10. Wang LJ, Wu HB, Wang M, Han YJ, Li HS, Zhou WL and Wang QS: Utility of F-18 FDG PET/CT on the evaluation of primary bone lymphoma. Eur J Radiol 84: 2275-2279, 2015.

11. Bansal S and Dharra N: Primary malignant non-hodgkin lymphoma of the talus. J Cancer Res Ther 11: 649, 2015.

12. Patel S, Sudesh P, John R and Gupta P: Primary non Hodgkin's lymphoma of talus in a child-a rare presentation. Foot (Edinb) 24: 210-212, 2014.

13. Kobayashi H, Kato Y, Hakamada M, Hattori Y, Sato A, Shimizu N, Imamura A, Mihara $\mathrm{H}$, Kato $\mathrm{H}$, Oki Y, et al: Malignant lymphoma of the bone associated with systemic sarcoidosis. Intern Med 40: 435-438, 2001.

14. Gill P, Wenger DE and Inwards DJ: Primary lymphomas of bone. Clin Lymphoma Myeloma 6: 140-142, 2005.

15. de Camargo OP, dos Santos Machado TM, Croci AT, de Oliveira CR, Giannotti MA, Baptista AM, Caiero MT, Alves VA and Matsumoto LA: Primary bone lymphoma in 24 patients treated between 1955 and 1999. Clin Orthop Relat Res 271-280, 2002.

16. Krishnan A, Shirkhoda A, Tehranzadeh J, Armin AR, Irwin R and Les K: Primary bone lymphoma: Radiographic-MR imaging correlation. Radiographics 23: 1371-1387, 2003.

17. Heyning FH, Kroon HM, Hogendoorn PC, Taminiau AH and van der Woude HJ: MR imaging characteristics in primary lymphoma of bone with emphasis on non-aggressive appearance. Skeletal Radiol 36: 937-944, 2007.

18. Akahane T, Shimizu T, Isobe K, Yoshimura Y and Kato H: Serum soluble interleukin-2 receptor levels in patients with malignant lymphoma of bone. J Orthop Sci 14: 248-252, 2009.

19. Moog F, Kotzerke J and Reske SN: FDG PET can replace bone scintigraphy in primary staging of malignant lymphoma. J Nucl Med 40: 1407-1413, 1999.

20. Heacock L, Weissbrot J, Raad R, Campbell N, Friedman KP, Ponzo F and Chandarana H: PET/MRI for the evaluation of patients with lymphoma: Initial observations. AJR Am J Roentgenol 204: 842-848, 2015.

21. Ramadan KM, Shenkier T, Sehn LH, Gascoyne RD and Connors JM: A clinicopathological retrospective study of 131 patients with primary bone lymphoma: A population-based study of successively treated cohorts from the British Columbia Cancer Agency. Ann Oncol 18: 129-135, 2007.

22. Jacobs AJ, Michels R, Stein J and Levin AS: Socioeconomic and demographic factors contributing to outcomes in patients with primary lymphoma of bone. J Bone Oncol 4: 32-36, 2014.

23. Maruyama D, Watanabe T, Beppu Y, Kobayashi Y, Kim SW, Tanimoto K, Makimoto A, Kagami Y, Terauchi T, Matsuno Y and Tobinai K: Primary bone lymphoma: A new and detailed characterization of 28 patients in a single-institution study. Jpn J Clin Oncol 37: 216-223, 2007.

24. Coiffier B,Lepage E, Briere J,Herbrecht R, Tilly H, Bouabdallah R, Morel P, Van Den Neste E, Salles G, Gaulard P, et al: CHOP chemotherapy plus rituximab compared with CHOP alone in elderly patients with diffuse large-B-cell lymphoma. N Engl J Med 346: 235-242, 2002.

25. Barbieri E, Cammelli S, Mauro F, Perini F, Cazzola A, Neri S, Bunkheila F, Ferrari S, Brandoli V, Zinzani P, et al: Primary non-Hodgkin's lymphoma of the bone: Treatment and analysis of prognostic factors for Stage I and Stage II. Int J Radiat Oncol Biol Phys 59: 760-764, 2004.

26. Baar J, Burkes RL, Bell R, Blackstein ME, Fernandes B and Langer F: Primary non-Hodgkin's lymphoma of bone. A clinicopathologic study. Cancer 73: 1194-1199, 1994.

27. Unni KK and Inwards CY: Malignant lymphoma of bone. In: Unni KK (ed): Dahlin's Bone Tumors, General aspects and data on 10,165 cases, 6th edition. Wolters Kluwer Health/Lippincott Williams \& Wilkins, Philadelphia, pp201-210, 2010. 